\title{
Enhancement, disability and the riddle of the relevant circumstances Hazem Zohny
}

Enhancement and disability are contentious concepts. Suppose you have access to a safe drug that allows you to draft manuscripts with astonishing speed, clarity and insight, while I, after a severe blow to the head, permanently find reading impossible as words now seem to keep jumping across the page. Are these changes to our respective capacities instances of enhancement and disability?

The welfarist account of these concepts gives an unusual answer: it depends. If your new ability to mass produce great manuscripts is likely to make your life go better, while my inability to read is likely to make my life go worse, then yes-you have been enhanced and I disabled. On the other hand, had we both been living in illiterate societies or eras with no use for reading or writing, then it is not clear there is anything enhancing or disabling about our new capacities. This is because, for the welfarist account, whether a loss or gain in capacities is enhancing or disabling depends on how such changes to our bodies and minds impact our well-being in our given circumstances.

To be more precise, the welfarist account defines an enhanced state as:Any state of a person's biology or psychology which increases the chances of leading a good life in the relevant set of circumstances. ${ }^{1}$

Hand in hand with this, the account defines a disabled state as:Any state of a person's biology or psychology which decreases the chances of leading a good life in the relevant set of circumstances. ${ }^{1}$

There are a number of counterintuitive implications to these definitions. For one, it suggests that even a loss or diminishment in a capacity may be enhancing for a person; for instance, a decline in the recall ability of someone suffering from post-traumatic stress disorder may improve their well-being overall, and therefore, count as an enhancement. ${ }^{2}$

While we will explore some of the other implications of this approach below, the prime focus here will be on the significance of this notion of 'relevant set of circumstances'. What constitutes these and what makes a given circumstance relevant or irrelevant when determining whether a state is enhancing or disabling? The obvious answer would seem to be that, if our focus is on the well-being of a person, then we ought to include whatever circumstances are relevant to that person's well-being. These may be physical, sociocultural, personal or anything else conceivably relevant to a person's well-being.

But consider one side effect of such inclusiveness. We may call this the 'mislabelling objection'_-the key issue that will occupy our concerns here. Imagine a person with dark skin in a set of circumstances where there is social prejudice against people with dark skin. If that prejudice reduces their chances of leading a good life, the welfarist account would have us conclude 
that dark skin (in such circumstances) is a disability. This seems strange; possibly offensively so. Is it relevant or coherent to call that person disabled? And were all, say, black slaves in the Americas disabled? Moreover, if a darkskinned person in a racist society underwent some intervention that gave them paler skin, presuming this improves their well-being by allowing them to sidestep prejudice, are they now enhanced?

Such a dubious use of labels seems problematic for the welfarist account. Or, at least, in introducing and elaborating on their welfarist definition of disability, Savulescu and Kahane imply that it is. ${ }^{3}{ }^{4}$ In fact, as we will see, they hold this as sufficiently troublesome so as to justify excluding social prejudice from the relevant circumstances that impact an individual's well-being when defining disability. That is, while the welfarist account holds any given bodily or mental state as potentially enhancing or disabling, if that state or any change to it improves or diminishes a person's well-being solely due to it being subject to social prejudice, then this considered a separate matter. The impact of social prejudice on well-being is simply not relevant to questions of enhancement and disability. We ought to deal with social prejudice by combating it, not by allowing it to determine whether someone has bodily or mental states that are enhancing or disabling. Or so Savulescu and Kahane have argued. ${ }^{3}$

While this may appear to sidestep the mislabelling objection, I will argue that it also defeats the purpose of the welfarist account. As we are about to see, the attractiveness of this account is in its ability to avoid a number of the conceptual difficulties facing other definitions of these concepts. It does so by offering a non-moralised, prudential account of them. However, by excluding social prejudice from the relevant circumstances, I argue the account ultimately loses this distinguishing feature. To state the argument to be presented simply: in trying to avoid the mislabelling objection, Savulescu and Kahane end up retreating to the very position that the welfarist account was designed to avoid. To see how, let us explore what that position is and how the welfarist account is meant to evade it.

\section{Elaborating on the welfarist account}

As we have seen, the primary concern of the welfarist account is well-beingor, more precisely, how a specific individual's biological and/or psychological states affect their chances of leading a good life, which I take to refer to their well-being. It is the impact of those states on a person's well-being that determines whether they are advantageous or disadvantageous, enhancing or disabling. In other words, the primary concern here is what is of prudential value to a person.

As Savulescu and Kahane make clear:If something leads to a reduction in someone's wellbeing, then that thing is bad for that person. This means that if something is a disability in our [welfarist] sense, then it is also a condition that makes life worse. ${ }^{4}$ 
Likewise, we might add, if something increases someone's well-being, then that thing is good for that person. Hence, enhancements here are any changes to one's biology or psychology that tend towards that end:

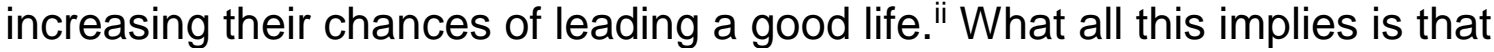
enhancements are simply alleviations of disabilities - that is, alleviations of bodily and mental states that are obstacles to greater well-being.

This point tells us what the account holds a person enhanced or disabled relative to: a person does not become enhanced or disabled relative to their previous capacities, and certainly not relative to the typical functioning of their species. Instead, they are enhanced or disabled relative to how well their life could possibly go given certain bodily and mental states.

This has a further counterintuitive implication: we are all disabled all the time, and to varying degrees. This is because we all arguably possess mental and bodily states that get in the way of us leading better lives. Hence, even a highly enhanced 'posthuman' may nevertheless be disabled on this account.

Unusual as this may seem, the key here is to remember that this is a stipulative account of these concepts: the account stems from a premise that our more common conceptions of these terms are inadequate and in need of upgrading if they are to capture what is of relevance to the nature and ethics of enhancement and disability.

To see how inadequate these more common conceptions are, note how they are typically expressed. Enhancement is most often characterised in functional terms as an intervention that augments our capacities in some way, ${ }^{5},{ }^{6}$ or more specifically, as an intervention that does so in a manner that goes beyond merely restoring health or preventing illness. ${ }^{7-10}$ In contrast, disability is often broadly understood in medical terms as some unfortunate deviation from species-typical functioning. ${ }^{11-13} \mathrm{iii}$

While the conceptual problems facing these accounts are numerous, ${ }^{1-}$ ${ }^{4},{ }^{14}$ what unites them is their failure to say anything about how disabled and enhanced states relate to well-being. On these functionalist accounts, a person who augments, say, their auditory capacities so they can hear everything within a mile has been enhanced, even if such a capacity leaves them chronically distracted and ultimately deeply neurotic (and therefore, we can assume, unable to lead a good life). Similarly on these accounts, a person who falls below species-typical functioning by becoming, say, deaf, is considered disabled, even if they are leading a life of much higher well-being than they otherwise would have due to, say, their enthusiastic immersion in a rich deaf culture, their enjoyment of a heightened sense of touch, along with the fact that they simply have no desire to hear.

More importantly, these accounts raise the question of what the moral relevance is of standards like species-typical functioning or 'normal' functioning. By defining these terms relative to one's prior state of health or one's species-typical functioning, the implication is that these standards serve 
as morally relevant reference points in and of themselves. And yet, without explicating how these reference point or boundaries are relevant to well-being, or at least some other uncontroversial value, their usage in characterising enhancement and disability reflects an arbitrarily moralised stance on the matter. On the other hand, what is the moral relevance of people leading a better or worse life? Some would say that is all that morally matters, or at least, it is certainly a cornerstone of what is relevant to ethics.

As such, by tying these concepts to well-being, the welfarist account allows us to avoid the moralised starting points and terminological controversies at the core of other accounts. It provides an inherently normative approach, giving us prima faciereasons to address conditions that are making an individual's life worse, as well as helping us understand why enhanced states can be desirable to begin with. ${ }^{1}$ This sets the groundwork for a germane and coherent framework from which to then think about what is at stake in regards to enhancement and disability without having to rely on controversial references to 'normality' or other morally arbitrary standards of functioning. In that way, the welfarist account sidesteps this moralising pitfall and keeps the focus on what actually matters in a given case: a person's well-being.

Nevertheless, this key advantage aside, a number of criticisms have been levelled against the welfarist account. Most of these have focused on its definition of enhancement, although they apply in similar ways to its definition of disability. For instance, it may be argued that this account loses contact with the everyday language use of the term enhancement, ${ }^{15}$ making it otiose since it does not explicitly distinguish therapy from enhancement. ${ }^{16}$ Others have suggested it is too dependent on the contested notion of a good life or well-being, ${ }^{17}$ and that it risks underestimating social pressures that influence individual choice, as well as the collective consequences of enhancement. ${ }^{18},{ }^{19}$

I have previously argued that these criticisms are either unfounded or addressable. ${ }^{14}$ What remains troubling about this account, however, is its emphasis on the 'relevant circumstances', and here we finally hone back in on the central issue. To start us off, why does it place such emphasis on a person's circumstances in its definitions of enhanced and disabled states?

The reason is straightforward: what makes leading a good life easier in one circumstance, may make it harder in another. One example Savulescu and Kahane give is our disposition to rest and store excess calories as fat: such a disposition is clearly advantageous in a set of circumstances where resources are limited, but it can lead to ultimately lethal consequences where there is an overabundance of resources. ${ }^{4}$ Similarly, while deafness is generally deemed a disadvantageous lack of a capacity, it may arguably be an advantage in an environment of consistently loud and extremely distracting noise. Even something as extreme as a brainstem stroke that leaves an individual unable to speak or move-most would agree that such a condition severely limits one's chances of leading a good life. Yet surely that is true only in relation to 
our broader circumstances. For instance, had we telepathic and telekinetic powers - that is, had our circumstances as human beings been very different-then perhaps such a lesion to the brain would not be considered so disabling (presuming the stroke did not affect those powers as well).

What this shows is that there is no context-independent answer to the question of whether a state increases or decreases the chances of leading a good life. The particular circumstances of the individual (which may include everything from the type of universe they inhabit, to their surrounding culture, to their personal life goals and desires) clearly play a determining role in answering that question.

And yet, this brings us back to the central conundrum raised briefly at the start: a person with dark skin whose set of (in this case, social) circumstances include prejudice against dark skin. The welfarist account may (mis?)label that person as disabled. Let us explore the nature of this mislabelling objection in more detail, including what it might mean for enhanced states.

\section{The mislabelling objection}

Again, consider a person with dark skin who lives in a racist society that diminishes their well-being by discriminating against dark-skinned individuals. Moreover, imagine this person hears of a new intervention that promises to make them significantly paler. Not wanting to spend their lives battling unjust discrimination, they agree to undergo it, and as a result are not discriminated against as often, increasing their prospects and income, and ultimately their level of well-being. ${ }^{\text {iv }}$

According to the welfarist account, this person has been enhanced. Indeed, since enhancements on this account are alleviations of disabilities, this person was disabled: they possessed a biological state or property (dark skin) that reduced their chances of leading a good life in their circumstances. Similarly, the account suggests that the homosexual who becomes heterosexual in a homophobic society, or even the woman who reassigns her gender in a misogynistic one, have become enhanced, if they are prudentially better off because of the change. Furthermore, those who do not undergo these modifications may be said to live with a disability.

Or consider societies where girls who have not undergone some form of female genital mutilation (FGM) are discriminated against, so much so that (we will presume) the loss of well-being from such a practice is outweighed by the loss of life prospects and basic, decent treatment by other members of her society. The welfarist account may have us label women who have undergone FGM as 'enhanced', with new interventions that facilitate that practice as 'enhancement technologies'. Indeed, according to the welfarist account, having a clitoris in such circumstances may count as a disability.

In these scenarios, the use of these labels seems troubling. On the one hand, the mislabelling objections acts to pump an intuition that something has gone 
amiss here-the account has simply lost the plot. And there may be good consequentialist reasons for thinking that. Superficially at least, there appears to be something politically incorrect here. Calling a pale skinned person or a straight person enhanced compared with being dark-skinned or gay-some may wish to argue that such labels are harmful regardless of the circumstances. And one reason for that might be that the use of these terms may act to validate or play into the already existing injustice within those societies. For instance, by labelling a girl who has had her clitoris removed enhanced, there may be a concern that such a positive label could reinforce the social forces behind the practice. Similarly, the 'disabled' who fail or refuse to undergo the 'enhancement' might risk further discrimination thanks to the stigmatising connotations that may be associated with the mere label of disabled. This may include subtler forms of discrimination such as aversive disablism: an unconscious prejudice against individuals considered disabled due to a belief that they are inferior to others. ${ }^{20}$

Moreover, there might be a concern that controversial enhancements on this account could be more easily assimilated as treatments within medicine. For instance, if being gay can be coherently labelled a disability-and it can be coherently labelled so on the welfarist account, given the right circumstances - then this may act in the favour of medicalising being gay and offering treatments for it. Indeed, it may help medicalise whatever biological or psychological states that victims of prejudice possess, further propagating the notion that they embody some lamentable deficiency. ${ }^{21}$

Nevertheless, the proponent of the welfarist account has a straightforward response to these concerns. First, we should remember that this account is not trying to define what types of biological or psychological states are inherently better. Rather, it is trying to capture what may be better or worse for a person in their circumstances - that is, what may be advantageous or disadvantageous for them. And, it is a matter of fact that being, say, gay or dark-skinned for some people in some circumstances is worse for them than being straight or white. It is purely this prudential dimension of their states that this account strives to capture. And while it may be true that there are negative connotations that follow from the label disabled, this is only due to an understanding of disability as some morally relevant deviation from normality, or as some condition warranting medical attention. Yet it is precisely such an understanding of disability that the welfarist account seeks to move us away from.

Furthermore, if the interventions discussed here (eg, somehow changing a person's sexual orientation to a conforming standard) were deemed to promote injustice, the welfarist account is compatible with regulating those interventions in whatever way we deem just, including banning them. The fact that an intervention may be of prudential value to someone does not in itself entail that it ought to be permissible. This is because the welfarist account is not a stance on the permissibility of enhancement, it is a merely a definition of the concept. ${ }^{14}$ While it highlights well-being as a starting point for thinking 
about enhanced and disabled states, how we ultimately decide to promote an individual's well-being and when would also be determined by other values such as justice, as well as whatever other values individuals or society think are relevant to ethical decision making. ${ }^{1}$ To be clear: nothing about the welfarist account entails that the promotion of individual well-being trumps all other values, let alone that such a promotion should be realised through biomedical means, as opposed to environmental changes.

\section{Excluding social prejudice (and why this fails)}

Despite this possible response by the proponent of the welfarist account, Kahane and Savulescu take a different track. ${ }^{3}{ }^{4}$ As I mentioned previously, they attempt to sidestep this issue of alleged mislabels by excluding social prejudice from their definition of disability-all at the expense, I argue, of robbing the account of its key advantage over other definitions. How do they do this?

While they define disability broadly as any state of a person's biology or psychology which decreases the chances of leading a good life in the relevant set of circumstances,$^{1}$ their more detailed analysis of the concept includes the addition of this clause: 'excluding the effect that this state has on well-being that is due to prejudice against that person by members of that person's society'. ${ }^{3}{ }^{4}$ Let us call the addition of this exclusionary clause to the welfarist definition of disability 'W2'.

What W2 entails is that if a biological property or state is reducing the wellbeing of a person solely because that state is an object of prejudice in their particular social circumstances, then that state does not constitute a disability. That is, W2 defines disability as the effect a bodily or mental condition has on well-being that results after we subtract the effect it has through social prejudice. ${ }^{3}$ This means that in the case of the dark-skinned person, or the homosexual, or the non-mutilated woman in societies that are prejudiced against them-these are victims of prejudice, not disability.

Indeed, Savulescu and Kahane adopt W2 precisely as 'it relieves us from having to claim that having dark skin colour in a racist society is a disability'. ${ }^{3}$

To more fully grasp what W2 entails, consider a more complex situation involving an individual bound to a wheelchair in a society that does little to accommodate them due to prejudice against individuals in wheelchairs. Here W2 would hold that, if this individual is disabled, it is not because of their loss of well-being due to social prejudice against them, but because their condition leaves them unable to, say, fully enjoy the benefits and/or joys of bipedal mobility. These are benefits that, even if their society had fully accommodated them, they still would not have access to (at least given current levels of technology). On the other hand, the added diminishment to their well-being from social prejudice against them-that does not form part of their disability. It is a separate issue that calls for a different response: to combat that social prejudice. Hence, an individual may be disabled and be a victim of prejudice 
against their disability, but that prejudice does not constitute part of their disability.

But what might the implications of W2 be on the welfarist definition of enhancement or enhanced states? While Kahane and Savulescu do not discuss this, given that enhancements act as alleviations of disabilities, a person with dark skin in a racist society who undergoes an intervention to have paler skin (and thereby, we will presume, improves their well-being) does not become enhanced; they were never disabled to begin with. Rather, they were affected by prejudice, not disability. The modifying intervention has merely helped them sidestep that prejudice, but it has not enhanced them in the way relevant to what W2 now tries to capture: changes to our biology or psychology that improve our well-being for reasons unrelated to social prejudice.

At this point, however, it is starting to become clear the welfarist account is no longer purely concerned with the prudential value of a person's bodily and mental states. Like the other accounts it critiques, it too has become moralised, making a value judgement on the sorts of circumstances that are relevant to whether states in our bodies and minds are disabling or enhancing. On the one hand, this value judgement may allow us to characterise disabilities in a more specific way. For instance, imagine being told of an old friend who has immigrated to another country only to become disabled soon after. You then inquire about the nature of their disability, and are told that they had fallen victim to racism. Here, the term disabled, even if understood as a reference to well-being, seems unhelpfully vague and distracts from what we might want to say is the real issue: racism. But by excluding social prejudice as W2 does, we can use the term to distinguish cases like these from ones where the nature of someone's disability is rooted in blameless forces, like physical laws and/or biological facts, as well as non-discriminatory social forces. This seems a useful and morally relevant distinction that our concepts should be able to make.

And yet, if it is useful or morally relevant distinctions that we are after, surely there are many more to be made. After all, this account is concerned with any biological or psychological state, hence whether one becomes, say, mildly cognitively impaired $(\mathrm{MCl})$ due to head trauma or due to old age is irrelevant. According to the welfarist account, including W2, both are, or can be, disabling. But most of us would think there is a relevant distinction here. For instance, $\mathrm{MCl}$ due to a head trauma at a young age tends to be perceived as tragic and warranting of treatment in a way that 'natural' $\mathrm{MCl}$ in old age is not and does not. So why not add a further clause to exclude well-being diminishing states that we might deem natural, such as $\mathrm{MCl}$ with old age? That would make the account more in line with our intuitions about what is relevant to disabilities. In fact, in regards to enhancements, why not add a further clause that excludes changes to the body or mind that may exacerbate injustice? Surely there is a relevant moral distinction between an enhancement that comes at little cost to others in society and ones that cause 
great societal harm (by, for instance, increasing discrimination against those who refuse or cannot afford to undergo the intervention).

The answer to these questions lies in what the welfarist account is concerned with highlighting: a person's well-being, not the ethical soundness of the circumstances that increase or diminish it. Again, it is designed to capture what is advantageous or disadvantageous for a person in their circumstances. Whether certain states ought to be advantageous or disadvantageous may be highly relevant questions to ask, but these would be ethical questions about prudential value: when it ought to be pursued, and how, and in what ways it ought to be distributed. Yet the welfarist account is explicitly formulated to help us non-judgementally answer the question of what states are good or bad for a specific person in a specific circumstance. Once we open the door to moralising this account, as this exclusionary clause in W2 does, this raises the question of why we should stop there and not add other boundaries to it. Indeed, it raises the question of why we should even consider this account over the other, more common, definitions that appeal to species-typical functioning or other morally arbitrary reference points.

Also, the issue of vagueness raised in the case of the old friend who has immigrated is not as problematic as it may seem. This is because even the everyday language use of the term 'disability' tells us little on its own about the nature of any given disability. Is it congenital? Is it due to an accident? How debilitating is it? The answers to such questions may have substantial consequences for how we respond to a given disability - for instance, whether we decide to treat it, and with what degree of priority, or whether we ought to change how our society is organised to accommodate it. Without these details, the label disability tells us very little. With that in mind, the welfarist definition would not make the concept any more vague in regards to a given individual. If we accept the welfarist account, we merely have to add other equally relevant questions to the ones above: is it due to old age? Is it due to social prejudice? Indeed, is it due to non-discriminatory social forces? It is not clear that a disability arising due to social prejudice would be unique in its impact on how we might perceive or respond to a person suffering from it.

Interestingly, despite adding this exclusionary clause, Savulescu and Kahane do not deny that social prejudice is relevant to disability. They present their welfarist account as an approach that occupies a middle ground between the medical and social models of disability. The medical model typically characterises disability as a stable property of a person that deviates (or falls below) the normal functioning of the human species. It reflects some deficiency or lack in motor, sensory or cognitive capacities that most people possess, implying that such a deficiency is also a misfortune that ought to be corrected if possible. ${ }^{11-13}$ In contrast, the social model does not see disability as an impairment in itself, but as the disadvantage or restriction of activity caused by a contemporary social organisation that takes little account of people who have physical impairments. ${ }^{22}$ Hence, for the social model, it is the unjust way through which society is organised that is disabling for some. $.^{23},{ }^{24}$ 
The welfarist account of disability seeks to occupy a middle ground between these two approaches in this way: like the medical model, it suggests that disabilities refer to conditions or states that an individual possesses. Like the social model, however, it denies that those conditions or states are, in and of themselves, morally significant or unfortunate. On the other hand, unlike the social model, the welfarist account disagrees that the only way disabilities reduce well-being is through social prejudice. But this is not to say that social prejudice is unrelated to disability. As they make clear:Advocates of the social model are no doubt right that some of the adverse effects of deviation from the species norm are due to such prejudice. We disagree, however, that all of the ways in which common disabilities can reduce wellbeing are entirely due to prejudice. $^{4}$

This suggests that the disagreement here is not that social prejudice is a separate matter to disability, but only that there is more to disability than mere social prejudice. Given such a concession, it seems strange that Kahane and Savulescu then go on to entirely exclude social prejudice from their definition once they formulate it as W2. The definition now appears to shun the very essence of the social model. W2 can, in principle, count any abiding condition as a disability, but not the one condition that, for the social model, is the condition: social prejudice. In that way, the welfarist account no longer seems to occupy a middle ground between the medical model and the social one. It now fails to capture the fact that disability can arise from how, both, discriminatory and non-discriminatory circumstances interact with our biological and psychological states to impact our well-being positively or negatively. More importantly, it now retreats to the very position it is designed to avoid: a moralised account with (what I have argued is) an arbitrary boundary built into its definitions.

\section{An alternative to excluding social prejudice}

Is there an alternative to avoiding the mislabelling objection, aside from excluding social prejudice? I think there is. It lies in the fact that this account seeks to capture the nature of advantageous and disadvantageous biological and psychological states. Indeed Kahane and Savulescu want to use these terms interchangeably with being enhanced or disabled. ${ }^{1}$

Given this intention, note how if we were to rely solely on the term 'disadvantageous states' instead of disability, the mislabelling objection seems to vanish. How so?

While it may seem perverse to call a dark-skinned person in a racist society disabled, it seems far less controversial to claim that, in a circumstance where social prejudice entails that having dark skin is disadvantageous, it is disadvantageous to possess dark skin. Having dark skin within such circumstances is a biological state that is disadvantageous precisely because it reduces the chances of leading a good life. Similarly, being gay in a homophobic society can be a disadvantageous state to the extent that it 
reduces the chances of leading a good life within such circumstances. It is coherent to say that being gay can be a disadvantageous state, but that it should not be. Such a description does not have the potentially discriminatory or medicalising connotations that arise when we use the label disabled for individuals in these situations. On the contrary, when society leaves people at a disadvantage because of prejudice, the connotation is that society should do better for them, not that they suffer from an unfortunate condition that ought to be 'fixed'.

Similarly, if one were to undergo a biomedical intervention that allowed them to sidestep social prejudice, we can say that they now possess more advantageous biological or psychological states. They are advantageous for them precisely because they enable them to sidestep that prejudice. And so, while it may seem wrong to call a dark-skinned person who becomes paler in a racist society enhanced, it is uncontroversial to argue that their paler skin is an advantageous biological state to possess in their particular circumstances, even if it is unfair that it is advantageous.

Based on this, if the welfarist account eschews terms like enhanced and disabled and adopts advantageous and disadvantageous states, it can sidestep the mislabelling objection, and there would be no pressure to add a clause excluding social prejudice from its definition of disability. The benefit of this is that it would enable the account to achieve what it sets out to achieve: to acknowledge that prejudice can play a role in making a certain biological or psychological state disadvantageous, but that disadvantageous states can certainly also arise for reasons unrelated to prejudicial social circumstances. In that sense, it can indeed occupy a middle ground between the social and medical models of disability, while also avoiding the retreat to being a moralised account.

But how satisfactory would such a substitution in terms be? While it may offer a simple solution, in practice it is arguably unlikely to catch on in the voluminous disability and enhancement literature, let alone in everyday speech. A compromise may be to increasingly interchange our use of enhanced and disabled with advantageous and disadvantageous states, until these acquire a synonymous relationship.

Here, we would not necessarily be biting the bullet on the mislabelling objection when we do periodically use the terms enhanced and disabled. Recall that the welfarist account seeks to undermine the notion that disability is a (necessarily) morally significant deviation from normality, or that disability entails a medical problem. It is, therefore, working to neutralise the negative connotations and societal attitudes that often accompany the label of being disabled. The more it is adopted, the less likely concerns related to the mislabelling objection would materialise.

Of course, the fact that the account seeks to undermine these negative connotations of disability does not mean it will succeed. It may be that even a well-being grounded expansion of the range of states that we consider 
disabling will nevertheless lead to prejudice against people with those states in the form of aversive disablism. That is, even with an increasingly accepted welfarist understanding of disability, we may still find that some will subject others who are understood as disabled to subtle forms of prejudice due to an entrenched notion that the disabled are inferior to others. Whether this will likely happen if we adopt the welfarist account and use the term disabled may be posed as an empirical question that invites investigation. Depending on the answer, we may wish to more confidently embrace the terms enhanced and disabled in the welfarist sense, or we may have to move away from them and settle for advantageous and disadvantageous states instead.

Either way, we can end by reiterating that the welfarist definitions of enhanced and disabled states are stipulative: they stem from a premise that our common conceptions of these terms are inadequate and in need of upgrading. If we do use the terms enhanced and disabled, we may have to accept that, in some situations, we will (perhaps somewhat awkwardly) label individuals as disabled or enhanced, despite the fact that this feels like an alien or injusticepromoting use of these words.

In such cases, we would need to remember that we are using these labels merely to describe states that are good or bad for a person in a certain circumstance, not states that are good or bad in and of themselves. In other words, we are merely describing states in terms of prudential value. But whether a given state ought to make a life go better or worse, and whether it ought to be promoted or avoided and in what ways-these are questions to be settled in conjunction with other values, such as justice. The welfarist account offers a solid framework to help us think about these further issues without being hampered by the terminological controversies and conceptual confusions of other accounts-so long, that is, as we resist the temptation of adding the moralising baggage that comes with excluding social prejudice.

\section{References}

1 Savulescu J, Sandberg A, Kahane G. Well-being and enhancement. In: Savulescu J, Meulen R ter, Kahane G, eds. Enhancing human capacities. Blackwell Publishing, 2011:1-18.

2 Earp BD, Sandberg A, Kahane G, et al. When is diminishment a form of enhancement? Rethinking the enhancement debate in biomedical ethics. Front Syst Neurosci 2014;8:12.

3 Kahane G, Savulescu J. The welfarist account of disability. In: Brownlee K, Cureton A, eds. Disability and disadvantadge. Oxford University Press, 2009:15-53.

4 Savulescu J, Kahane G. Disability: a welfarist approach. Clin Ethics $2011 ; 6: 45-51$. 
5 Engelbart DC. Augmenting human intellect: a conceptual framework. In: Packer R, Jordan K, eds. Multimedia from Wagner to virtual reality. New York: WW Norton \& Company 1962:64-90.

6 Bostrom N, Roache R. Ethical issues in human enhancement. In: Ryberg J, Petersen T, Wolf C, eds. New Waves in Applied Ethics. Basingstoke: Palgrave Macmillan, 2007:120-152.

7 Juengst E. What does enhancement mean? In: Parens E, ed. Enhancing human traits: ethical and social implications. Georgetown: Georgetown University Press, 1998:29-47.

8 Daniels N. Normal functioning and the treatment-enhancement distinction. Camb Q Healthc Ethics 2000;9:309-22.

9 Resnik DB. The moral significance of the therapy-enhancement distinction in human genetics. Camb Q Healthc Ethics 2000;9:365-77.

10 Pellegrino E. Biotechnology, Human Enhancement, and the Ends of Medicine. 2004. https://cbhd.org/content/biotechnology-human-enhancementand-ends-medicine (accessed 7 May 2015).

11 Areheart BA. When disability isn't just right: the entrenchment of the medical model of disability and the goldilocks dilemma. Ind LJ 2008;83:181.

12 LA Eichhorn. Hostile Environments, Title VII, and the ADA: The Limits of the Copy and Paste Function. Washington Law Review n.d.;77:575.

13 Silvers A, Wasserman DT, Mahowald MB. Disability, difference, discrimination: perspectives on justice in bioethics and public policy. Rowman \& Littlefield, 1998.

14 Zohny $\mathrm{H}$. A defence of the welfarist account of enhancement. Performance Enhancement \& Health 3.3. 2014:123-9.

15 Sparrow R. Queerin' the PGD Clinic. J Med Humanit 2013;34:177-96.

16 Coenen C, Schuijff M, Smits M. The politics of human enhancement and the European Union. In: Savulescu J, Meulen R ter, Kahane G, eds. Enhancing Human Capacities. Blackwell Publishing, 2011:521-35.

17 Beck B, Stroop B. A biomedical shortcut to (Fraudulent) happiness? An analysis of the notions of well-being and authenticity underlying objections to mood enhancement. In: Søraker JH, Rijt J-WV der, Boer J de, et al., eds. Well-Being in Contemporary Society, Springer International Publishing. 2015:115-34.

18 Camporesi S. From bench to bedside, to track \& field. San Francisco, CA: University of California Medical Humanities Press, 2014. 
19 Gordon R. Enhancement and Social Possibility. The Neuroethics Blog, 2014. http:// www.theneuroethicsblog.com/2014/08/enhancement-and-socialpossibility.html\#more (accessed 8 Aug 2014).

20 Deal M. Aversive disablism: subtle prejudice toward disabled people. Disabil Soc 2007;22:93-107.

21 Titchkosky T. Disability: a rose by any other name? "People-First" language in Canadian Society*. Can Rev Sociol 2001;38:125-40.

22 UPIAS. Fundamental Principles of Disability. 1976.

23 Koch $\mathrm{T}$. Disability and difference: balancing social and physical constructions. J Med Ethics 2001;27:370-6.

24 Amundson R. Disability, ideology, and quality of life. In: Wasserma D, Bickenbach J,eds. Quality of life and human difference. Genetic Testing, Health Care and Disability, 2005:101-20. 